\title{
Trichoderma spp. na Produção de Mudas de Espécies Florestais
}

\author{
Emanuele Junges ${ }^{1}$, Marlove Fátima Muniz ${ }^{2}$, Ricardo Mezzomo², Bruna Bastos², \\ Rodrigo Tascheto Machado ${ }^{2}$
}

\author{
${ }^{1}$ Setor de Defesa Fitossanitária, Instituto Federal Farroupilha, São Vicente do Sul/RS, Brasil \\ ${ }^{2}$ Departamento de Defesa Fitossanitária, Universidade Federal de Santa Maria, Santa Maria/RS, Brasil
}

\begin{abstract}
RESUMO
Sementes sadias e rápido desenvolvimento de plântulas de espécies florestais nativas são fundamentais para o seu estabelecimento. Este trabalho avaliou o efeito de Trichoderma spp. sobre sementes e o desenvolvimento de plântulas de Parapiptadenia rigida (angico), Cedrela fissilis (cedro) e Pelthophorum dubium (canafistula). O fungo foi aplicado em diferentes momentos da produção de mudas. Sua ação foi diferenciada entre as espécies, bem como, entre as variáveis analisadas. O cedro foi menos responsivo à aplicação de Trichoderma spp. em qualquer momento da produção de mudas. A associação de Trichoderma spp. com angico, via tratamento de sementes, favoreceu a incidência de alguns patógenos, entretanto a aplicação mais tardia do fungo favoreceu o desenvolvimento da parte aérea. Sobretudo, em canafístula, o tratamento de sementes proporcionou controle de patógenos associados à semente e favoreceu a emergência e a produção de folhas nas mudas, apresentando potencial para ser usado tratamento de sementes desta espécie.
\end{abstract}

Palavras-chave: promotor de crescimento, sementes, tratamento de sementes.

\section{Trichoderma spp. in the Production of Seedling of Forest Species}

\begin{abstract}
Seeds healthy and rapid development of seedlings of native species may be critical to the success of your establishment. This study evaluated the effect of Trichoderma spp. on seed and seedling development of Parapiptadenia rigida (angico), Cedrela fissilis (cedro) and Pelthophorum dubium (canafistula). The fungi was applied at different times of the production of seedlings. The fungi action was different between species and between the variables. Cedro was less responsive to application of Trichoderma spp. at any time of the seedlings production and the association of Trichoderma spp. With angico as the seed treatment favored the incidence of some pathogens, however the application later favored only the leaves development. In canafístula, the seed treatment provided control of pathogens associated and stimulated the emergence and production of leaves in seedlings, have potential to be used for seed treatment of this species.
\end{abstract}

Keywords: growth promoter, seeds, seeds treatment. 


\section{INTRODUÇÃO}

Espécies florestais que possuem madeira com importância na construção civil ou de interesse paisagístico, estão com sua preservação ameaçada, devido a exploração de forma extrativista, ao desmatamento, às queimadas e a expansão de cultivos agrícolas, Estudos sobre manutenção da viabilidade das sementes após a colheita e a potencialização da produção de mudas são práticas fundamentais para a manutenção dessas espécies (Sarmento \& Villela, 2010).

Parapiptadenia rigida (Benth.) Brenan (angico) é uma espécie recomendada para recuperação de solos de baixa fertilidade natural e revegetação de áreas degradadas. É de fácil identificação devido ao seu porte, ao tronco com casca escamante e, pela madeira vermelha e dura. É uma espécie bastante agressiva, cresce espontaneamente ao longo de estradas, em beira de rios ou capoeiras (Backes \& Irgang, 2002). Apesar de produzir grande quantidade de sementes, ela possui característica recalcitrante, perdendo a viabilidade rapidamente o que dificulta sua propagação via sexuada (Carvalho, 2003).

As sementes de Pelthophorum dubium (Spreng.) Taub (canafístula) apresentam dificuldade em germinar devido à presença de tegumento rígido que impede a penetração da água e o desencadeamento dos processos metabólicos inerentes à germinação (Salerno et al., 1996). O máximo potencial de germinação é apresentado no início do processo de dispersão, quando predominam sementes duras, ocorrendo declínio após isso (Nakagawa et al., 2010).

Cedrela fissilis Vell. (cedro) é uma espécie arbórea nativa que produz madeira de alta qualidade e que vem sendo dizimada pela exploração extrativista na busca por madeiras nobres. Borges et al. (1990) demonstraram que a viabilidade das sementes de cedro está relacionada com a reserva de carboidratos e com a permeabilidade da membrana.

Portanto, deve-se manejar as sementes, visando aumentar a viabilidade destas e a produção de mudas com maior qualidade, assim como reduzir a população de fungos associados às sementes, para que as reservas não sejam destruídas e essas não se tornem veículos de disseminação de patógenos.

Um eficiente sistema de controle de patógenos em sementes, causadores de tombamento e morte de plântulas e das podridões radiculares é a introdução de bioprotetores por meio da microbiolização, definida como a aplicação de micro-organismos vivos ou de seus metabólitos na proteção de sementes, sendo este método já utilizado na promoção de germinação $\mathrm{e}$ crescimento e, no controle de diferentes patógenos (Faria et al., 2003). Muitos micro-organismos têm sido estudados, bem como a técnica utilizada para incorporação dos esporos dos fungos junto às sementes (Harman, 2000).

Trichoderma spp. têm se destacado como bioprotetor, por atuar como antagonista de alguns fitopatógenos de importância econômica e também por promover o crescimento e florescimento de plantas. Além disso, Trichoderma spp. são fungos simbiontes endofíticos de plantas amplamente utilizados no tratamento de sementes para controle de doenças e promover o crescimento e produtividade das plantas (Mastouri et al., 2010) por meio da solubilização de micronutrientes insolúveis no solo e proporcionando maior absorção e translocação de minerais pouco disponíveis.

Devido à importância da produção de mudas das espécies mencionadas, o trabalho teve como objetivo avaliar a influência do antagonista Trichoderma spp. sobre a sanidade de sementes e aspectos da qualidade de mudas de angico, cedro e canafístula quando aplicado em diferentes momentos da produção.

\section{MATERIAL E MÉTODOS}

Foram utilizadas sementes de Pelptophorum dubium (Spreng.) Taub (canafístula), Parapiptadenia rigida (Benth.) Brenan (angico) e Cedrela fissilis Vell (cedro), adquiridas do banco de sementes do Laboratório de Análise de Sementes da Fundação Estadual de Pesquisa Agropecuária - FEPAGRO, localizado em Santa Maria, RS. Foi realizada superação de dormência nas sementes de canafístula, por meio de imersão em água fervente por cinco minutos, seguida de 24 horas de imersão em água em temperatura ambiente (Oliveira et al., 2003). Para cedro e angico nenhuma forma de superação de dormência foi adotada.

A determinação da germinação das sementes a serem utilizadas foi conduzida com quatro repetições de 25 sementes para cada espécie, distribuídas em rolos de papel filtro umedecido com água destilada e esterilizada, equivalente a 2,5 vezes o peso do papel seco, 
e mantidos em germinador $\left(20-30^{\circ} \mathrm{C}\right.$, fotoperíodo $\left.12 \mathrm{~h}\right)$. A contagem foi realizada aos 15 dias após a semeadura. Os resultados foram expressos em percentagem média de sementes germinadas (Brasil, 2009).

Na avaliação da sanidade, sementes sem tratamento e com aplicação de formulado em pó de Trichoderma spp. foram colocadas em caixas "gerbox" contendo três folhas de papel filtro umedecidas com herbicida (2.4D amina) para inibir a germinação, incubadas a $25^{\circ} \mathrm{C}$ por sete dias, com fotoperíodo de $12 \mathrm{~h}$. Foram utilizadas 100 sementes por tratamento, para cada espécie, divididas em quatro repetições de 25 sementes. Após o período de incubação, as sementes foram analisadas sob microscópio estereoscópio e ótico para a detecção e identificação dos fungos associados às mesmas. A identificação dos fungos foi feita em nível de gênero e os resultados foram expressos em percentagem de sementes colonizadas por fungos (Maciel et al., 2012).

O antagonista Trichoderma spp. foi repicado para arroz estéril, mantido a $25^{\circ} \mathrm{C}$ e fotoperíodo de $12 \mathrm{~h}$ por 15 dias, o arroz colonizado foi seco e triturado até produção de pó. Cada grama de pó obtido continha $10^{6}$ UFC (Unidades Formadoras de Colônias). O tratamento das sementes foi realizado aplicando-se $1 \mathrm{~g}$ do pó em 100 sementes, homogeneizando levemente. A aplicação no substrato foi realizada misturado o pó em água destilada afim de se obter uma suspensão de esporos na proporção de $1 \mathrm{~g}$ para cada $200 \mathrm{~mL}$ de água. A cada $500 \mathrm{~g}$ de substrato ${ }^{-1}$ padrão da Fepagro para produção de mudas foram adicionados $200 \mathrm{~mL}$ da suspensão.

Trichoderma spp. foi testado em diferentes momentos do processo de produção das mudas, conforme os seguintes tratamentos: T1- rega do substrato com a suspensão de esporos 20 dias antes da semeadura; T2- aplicação nas sementes no momento da semeadura; T3- rega do substrato com a suspensão de esporos feita no momento da semeadura; T4- rega do substrato com a suspensão de esporos 20 dias após a semeadura; T5- Testemunha.

Foi realizado um ensaio para avaliação da qualidade das mudas, as sementes das espécies em estudo foram semeadas em tubetes, utilizando 100 sementes de cada espécie para cada tratamento. Foram realizadas as seguintes avaliações: emergência aos dez, 30 e 60 dias: contagem do número de mudas emergidas aos dez, 30 e aos 60 dias após a semeadura. Os resultados foram expressos em percentagem de emergência; avaliação final da qualidade das mudas feita aos 60 dias após a semeadura, quando as mudas foram arrancadas e avaliadas conforme: número de folhas, onde foi contabilizado o número de folhas verdadeiras em cada muda, expressando-se os resultados em número médio de folhas por planta; comprimento da muda, medida da distância entre a base do caule e o ápice do feixe de folhas, feita com o auxílio de régua milimétrica, $\mathrm{e}$ expressa em centímetros; diâmetro do colo, medido com paquímetro digital e expresso em milímetros; comprimento e massa seca das raízes e parte aérea de mudas, estas foram acondicionadas em sacos de papel e mantidas em estufa com ventilação forçada a $60^{\circ} \mathrm{C}$ por $48 \mathrm{~h}$ e então pesadas. Os resultados foram expressos em gramas/planta ${ }^{-1}$.

Foi utilizado o delineamento experimental inteiramente casualizado com quatro repetições para todos os ensaios. Para a avaliação da emergência, os tratamentos foram arranjados em um esquema fatorial 5X3 (tratamentos X dias após a semeadura). Para as demais avaliações não houve arranjo fatorial. Os valores percentuais foram transformados por raiz quadrada com $\mathrm{k}=100$ e as médias foram comparadas pelo teste de Duncan a 1\% de significância. Utilizou-se o Programa Estatístico SISVAR 5.3 (Ferreira, 2010).

\section{RESULTADOS E DISCUSSÃO}

As sementes das três espécies apresentaram baixa qualidade fisiológica inicial, com percentuais de germinação de 68, 7 e 26\% para canafístula, cedro e angico, respectivamente. Mesmo com esses resultados iniciais de germinação, optou-se pela realização dos tratamentos, por tratar-se da real situação de qualidade das sementes de espécies florestais comercializadas e disponibilizadas para semeadura. Carvalho et al. (2000) enfatizam que as melhores respostas a testes e tratamentos que visam melhoria no desempenho das sementes, são obtidos em sementes de baixa qualidade.

As variáveis não seguiram comportamento semelhante para todos os tratamentos e em todas as espécies. Na avaliação da sanidade de sementes de canafístula (Tabela 1), o bioestimulador apresentou elevado potencial de associação às sementes, colonizando $100 \%$ destas, com esporulação abundante, controlando todos os fungos associados. 
Tabela 1. Sanidade de sementes de Pelptophorum dubium (canafístula), Cedrela fissilis (cedro) e Parapiptadenia rigida (angico) submetidas a tratamento com Trichoderma spp.

Table 1. Health of seeds of Pelptophorum dubium (canafístula), Cedrela fissilis (cedro) and Parapiptadenia rigida (angico) submitted the treatment with Trichoderma spp.

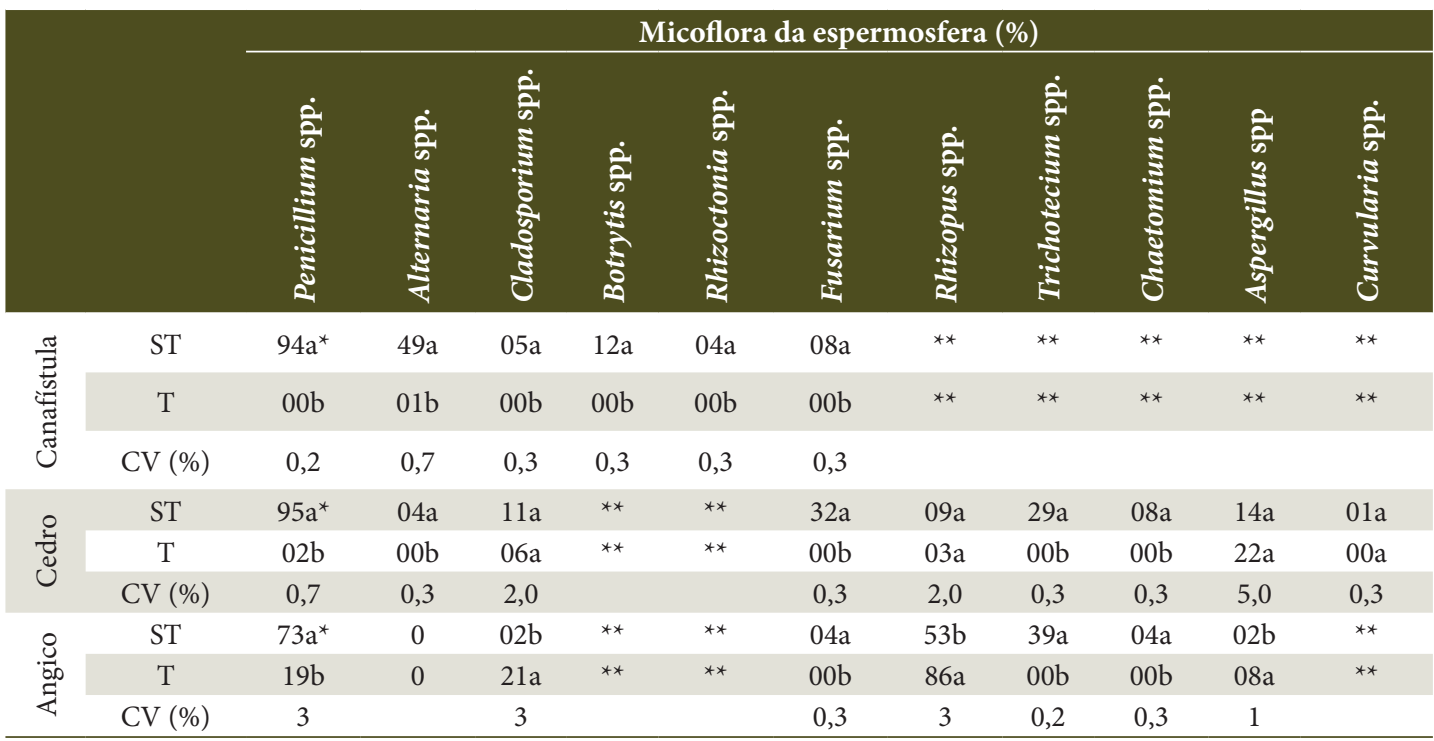

* Médias seguidas pela mesma letra nas colunas não diferem pelo teste de Duncan a $1 \%$ de probabilidade de erro. ${ }^{* *}$ Não houve incidências destes gêneros. ST: sem Trichoderma spp. T: com Trichoderma spp.

A desuniformidade de resposta das variáveis e das espécies para os tratamentos pode ser explicado pelos relatos de que Trichoderma spp. exibe variabilidade entre as linhagens com relação a atividades de biocontrole, espectro de ação contra os hospedeiros, propriedades fisiológicas e bioquímicas e adaptabilidade ecológica e ambiental influenciando seu desempenho como bioprotetor e promotor de crescimento de plantas (Silva, 2000). Bernardo \& Bettiol (2010) destacaram que o isolado de T. harzianum, isolado do solo, não foi eficiente no controle da pinta preta dos citrus em laranja 'Pêra' devido a não adaptação ao ambiente de parte aérea que foi aplicado, ou ainda, que o isolado não apresenta eficiência para aquele patossistema que foi testado.

Para cedro (Tabela 1), a microbiolização foi eficiente no controle de Penicillium spp., Alternaria spp., Fusarium spp., Trichotecium spp. e Chaetomium spp. porém não obteve o mesmo desempenho para Cladosporium spp., Rhizopus spp., Aspergillus spp. e Curvularia spp. Todas as sementes foram colonizadas, mas a esporulação foi menos favorecida.

Já a associação de Trichoderma spp. e angico foi menos expressiva do que para as outras espécies, apenas $65 \%$ das sementes foram colonizadas e da mesma forma, o controle dos patógenos associados também foi menos eficiente (Tabela 1). Foram controlados os fungos Penicillium spp., Fusarium spp., Trichotecium spp. e Chaetomium spp. Já Cladosporium spp., Rhizopus spp. e Aspergillus spp. incidiram mais sobre as sementes tratadas.

O uso de Trichoderma spp. para microbiolização de sementes foi eficiente no controle dos fungos associados e esta eficiência de controle foi maior quando a associação com a semente foi mais expressiva, assim como Howell et al. (1997), aplicando Trichoderma virens na forma granular em sementes de algodão, obtiveram colonização das raízes, reduzindo a colonização destas por Fusarium spp. e promoveu a supressão da murcha em algodão causada por F. oxysporum f. sp. vasinfectum. Sivan \& Chet (1989) constataram que a adição de conídios de Trichoderma harzianum (T-35) no solo ou em sementes reduziu a taxa de germinação de clamidósporos de Fusarium oxysporum f. sp. Vasinfectum e F. oxysporum f. sp. Melonis em algodoeiro e meloeiro, respectivamente.

$\mathrm{Na}$ avaliação da emergência (Tabela 2), não foi identificada interação entre os tratamentos e os 
períodos de avaliação. Para canafístula, a aplicação via semente apresentou o melhor resultado, apesar de ter diferenciado apenas da aplicação 20 dias antes da semeadura, promoveu elevação de $7,3 \%$ em relação à testemunha. Para cedro, a aplicação 20 dias antes promoveu 3\% a mais de plântulas emergidas em relação à testemunha, porém diferiu apenas da aplicação via substrato. Para angico, a aplicação de Trichoderma spp. via semente prejudicou a emergência das plântulas, reduzindo $35,9 \%$ em relação às sementes sem tratamento.

Tabela 2. Média das três avaliações de emergência de plântulas de Pelptophorum dubium (canafístula), Cedrela fissilis (cedro) e Parapiptadenia rigida (angico) submetidas a tratamento com Trichoderma spp.

Table 2. Average of the three evaluations of emergency of seedling Pelptophorum dubium (canafístula), Cedrela fissilis (cedro) and Parapiptadenia rigida (angico) submitted the treatment with Trichoderma spp.

\begin{tabular}{lccc}
\multirow{2}{*}{ Tratamentos } & \multicolumn{3}{c}{ Emergência (\%) } \\
\cline { 2 - 4 } & Canafístula & Cedro & Angico \\
\hline $\begin{array}{l}\text { T1-Substrato } \\
\text { 20 dias antes da } \\
\text { semeadura }\end{array}$ & $31,7 \mathrm{~b}^{*}$ & $9,0 \mathrm{a}$ & $44,3 \mathrm{a}$ \\
$\begin{array}{l}\text { T2-Substrato } \\
\text { 20 dias após a } \\
\text { semeadura }\end{array}$ & $33,7 \mathrm{ab}$ & $6,7 \mathrm{ab}$ & $43,4 \mathrm{a}$ \\
T3-Semente & $43,5 \mathrm{a}$ & $6,2 \mathrm{ab}$ & $16,3 \mathrm{~b}$ \\
T4-Substrato & $34,8 \mathrm{ab}$ & $3,1 \mathrm{~b}$ & $45, \mathrm{a}$ \\
\hline T5-Testemunha & $36,2 \mathrm{ab}$ & $6,0 \mathrm{ab}$ & $52,2 \mathrm{a}$ \\
CV \% & 3 & 2 & 4 \\
\hline
\end{tabular}

* Médias seguidas pela mesma letra nas colunas não diferem pelo teste de Duncan a $1 \%$ de probabilidade de erro.
O aumento da emergência de plântulas de canafístula (Tabela 2), cujas sementes foram tratadas com Trichoderma spp., pode ter sido favorecida pelo controle de patógenos associados. Segundo Mafia et al. (2003), a veiculação de Trichoderma spp. em grânulos de alginato de sódio com farelo de trigo como fonte alimentar, permitindo 18 dias de competição, exerceu controle sobre Rhizoctonia solani na propagação clonal de Eucalyptus spp. Takada (2004) aplicando Trichoderma spp. formulado em pó, no substrato estéril de cultivo de Eucaliptus urograndis, obteve a menor mortalidade de plântulas, possivelmente por sua ação antagônica à Rhizoctonia sp. Já para angico e cedro não houve melhoria na emergência.

Na avaliação da qualidade das mudas de canafístula (Tabela 3) ocorreu diferença entre os tratamentos para o número de folhas por muda, quando a aplicação via semente produziu maior enfolhamento da parte aérea das mudas, diferindo entre si com a aplicação mais tardia do bioestimulador. De mesma maneira, Prates et al. (2006), observaram que, em condições de campo, a aplicação do fungo antagonista no substrato de mudas de citrus, refletiu em produção de mais folhas, estas com coloração verde mais intensa e também, com maior desenvolvimento da raiz pivotante e de radicelas.

Para cedro (Tabela 4) apenas foi verificada ação dos tratamentos sobre o comprimento da parte aérea, onde a aplicação mais tardia produziu mudas com parte aérea maior, já a aplicação via substrato foi

Tabela 3. Qualidade de mudas de Pelptophorum dubium (canafístula) tratadas com Trichoderma spp. em diferentes momentos do processo de produção de mudas, avaliadas 60 dias após o plantio.

Table 3. Quality of seedling of Pelptophorum dubium (canafistula) submitted the treatment with Trichoderma spp. at different moments of the process of production of seedling, evaluated 60 days after the plantation.

\begin{tabular}{|c|c|c|c|c|c|c|c|c|}
\hline & \multicolumn{3}{|c|}{ Comprimento (cm) } & \multirow{2}{*}{$\begin{array}{l}\text { Número } \\
\text { de folhas }\end{array}$} & \multirow{2}{*}{$\begin{array}{c}\text { Diâmetro } \\
\text { de colo } \\
(\mathrm{mm})\end{array}$} & \multicolumn{3}{|c|}{ Fitomassa seca (mg) } \\
\hline & $\begin{array}{l}\text { Parte } \\
\text { aérea }\end{array}$ & Raiz & Total & & & $\begin{array}{l}\text { Parte } \\
\text { aérea }\end{array}$ & Raiz & Total \\
\hline $\begin{array}{l}\text { T1-Substrato } \\
20 \text { dias antes da } \\
\text { semeadura }\end{array}$ & $8,1 a^{*}$ & $12,5 \mathrm{a}$ & $20,7 \mathrm{a}$ & $4,3 \mathrm{ab}$ & $1,6 \mathrm{a}$ & $97,0 \mathrm{a}$ & $53,0 \mathrm{a}$ & $150,0 \mathrm{a}$ \\
\hline $\begin{array}{l}\text { T2-Substrato } \\
20 \text { dias após a } \\
\text { semeadura }\end{array}$ & $7,6 a$ & $12,4 \mathrm{a}$ & $20,0 \mathrm{a}$ & $4,1 b$ & $1,5 \mathrm{a}$ & $80,0 \mathrm{a}$ & $40,0 \mathrm{a}$ & $120,0 \mathrm{a}$ \\
\hline T3-Semente & $7,9 \mathrm{a}$ & $12,7 \mathrm{a}$ & $20,7 a$ & $4,7 \mathrm{a}$ & $1,5 \mathrm{a}$ & $89,5 \mathrm{a}$ & $41,0 \mathrm{a}$ & $130,5 \mathrm{a}$ \\
\hline T4-Substrato & $7,8 \mathrm{a}$ & $12,4 \mathrm{a}$ & $20,2 \mathrm{a}$ & $4,4 \mathrm{ab}$ & $1,6 \mathrm{a}$ & $93,5 a$ & $45,5 \mathrm{a}$ & $139,0 \mathrm{a}$ \\
\hline T5-Testemunha & $8,1 \mathrm{a}$ & $12,2 \mathrm{a}$ & $20,4 a$ & $4,4 \mathrm{ab}$ & $1,6 \mathrm{a}$ & $89,0 \mathrm{a}$ & $42,0 \mathrm{a}$ & $131,0 \mathrm{a}$ \\
\hline $\mathrm{CV} \%$ & 9 & 7 & 5 & 8 & 9 & 20 & 21 & 18 \\
\hline
\end{tabular}

* Médias seguidas pela mesma letra nas colunas não diferem pelo teste de Duncan a 1\% de probabilidade de erro. 
responsável por mudas menos desenvolvidas. A ação dos tratamentos foi compensada pelo crescimento radicular, uma vez que o comprimento total não diferiu entre os tratamentos.

Para angico (Tabela 5) a aplicação via semente produziu melhor desempenho do crescimento da parte aérea, já para comprimento radicular, o melhor resultado ocorreu na aplicação feita mais cedo, mas não houve diferença no comprimento total. Fortes et al. (2007), verificaram que isolados de Trichoderma spp. aplicados ao substrato aumentaram a porcentagem de enraizamento e sobrevivência de microestacas de Eucalyptus sp. Segundo Prates et al. (2007) o tratamento do substrato de mudas de laranja Pêra/ Limão cravo com Trichoderma spp., proporcionou maior comprimento e superfície total de raízes, o que refletiu em maior absorção de água, nutrientes e maior vigor.

A presença do bioprotetor pode ser fundamental após o transplante, quando as mudas estarão mais expostas a patógenos. Segundo Harman et al. (2004), Trichoderma spp. estimula a expressão de genes relacionados com a defesa da planta, processo similar ao de resistência adquirida. Patekoski \& Pires-Zottarelli (2010) observaram que o produto Biotrich, a base de Trichoderma spp., na concentração de $0,2 \mathrm{~mL} \mathrm{~L}^{-1}$ não promoveu o crescimento de alface in vitro e in vivo, porém controlou o patógeno Pythium aphanidermatum potencialmente destrutivo a cultivos hidropônicos.

Tabela 4. Qualidade de mudas de Cedrela fissilis (cedro) tratadas com Trichoderma spp. em diferentes momentos do processo de produção de mudas, avaliadas 60 dias após o plantio.

Table 4. Quality of seedling of Cedrela fissilis (cedro) submitted the treatment with Trichoderma spp. at different moments of the process of production of seedling, evaluated 60 days after the plantation.

\begin{tabular}{|c|c|c|c|c|c|c|c|c|}
\hline & \multicolumn{3}{|c|}{ Comprimento $(\mathrm{cm})$} & \multirow[b]{2}{*}{$\begin{array}{l}\text { Número } \\
\text { de folhas }\end{array}$} & \multirow{2}{*}{$\begin{array}{c}\text { Diâmetro } \\
\text { de colo } \\
\text { (mm) }\end{array}$} & \multicolumn{3}{|c|}{ Fitomassa seca (mg) } \\
\hline & $\begin{array}{l}\text { Parte } \\
\text { aérea }\end{array}$ & Raiz & Total & & & $\begin{array}{l}\text { Parte } \\
\text { aérea }\end{array}$ & Raiz & Total \\
\hline $\begin{array}{l}\text { T1-Substrato } 20 \text { dias } \\
\text { antes da semeadura }\end{array}$ & $3,8 \mathrm{ab}^{*}$ & $7,2 \mathrm{a}$ & $10,9 a$ & $2,0 \mathrm{a}$ & $4,3 \mathrm{a}$ & $38,7 \mathrm{a}$ & $17,4 \mathrm{a}$ & $56,1 \mathrm{a}$ \\
\hline $\begin{array}{l}\text { T2-Substrato } 20 \text { dias } \\
\text { após a semeadura }\end{array}$ & $4,4 \mathrm{a}$ & $8,6 a$ & $13,0 \mathrm{a}$ & $2,1 \mathrm{a}$ & $4,2 \mathrm{a}$ & $54,1 \mathrm{a}$ & $21,8 \mathrm{a}$ & $75,9 \mathrm{a}$ \\
\hline T3-Semente & $3,6 \mathrm{ab}$ & $6,6 a$ & $10,2 \mathrm{a}$ & $1,9 \mathrm{a}$ & $4,5 \mathrm{a}$ & $37,1 \mathrm{a}$ & $17,1 \mathrm{a}$ & $54,1 \mathrm{a}$ \\
\hline T4-Substrato & $2,1 b$ & $4,6 a$ & $6,6 a$ & $1,3 a$ & $3,2 \mathrm{a}$ & $18,0 \mathrm{a}$ & $7,6 a$ & $25,6 \mathrm{a}$ \\
\hline T5-Testemunha & $2,7 \mathrm{ab}$ & $5,9 a$ & $8,6 a$ & $1,4 \mathrm{a}$ & $2,7 \mathrm{a}$ & $32,6 a$ & $12,5 \mathrm{a}$ & $45,1 \mathrm{a}$ \\
\hline $\mathrm{CV} \%$ & 39 & 49 & 45 & 35 & 35 & 63 & 72 & 64 \\
\hline
\end{tabular}

* Médias seguidas pela mesma letra nas colunas não diferem pelo teste de Duncan a $1 \%$ de probabilidade de erro.

Tabela 5. Qualidade de mudas de Parapiptadenia rigida (angico) tratadas com Trichoderma spp. em diferentes momentos do processo de produção de mudas, avaliadas 60 dias após o plantio.

Table 5. Quality of seedling of Parapiptadenia rigida (angico) submitted the treatment with Trichoderma spp. at different moments of the process of production of seedling, evaluated 60 days after the plantation.

\begin{tabular}{|c|c|c|c|c|c|c|c|c|}
\hline & \multicolumn{3}{|c|}{ Comprimento $(\mathrm{cm})$} & \multirow{2}{*}{$\begin{array}{l}\text { Número } \\
\text { de folhas }\end{array}$} & \multirow{2}{*}{$\begin{array}{c}\text { Diâmetro } \\
\text { de colo } \\
\text { (mm) }\end{array}$} & \multicolumn{3}{|c|}{ Fitomassa seca (mg) } \\
\hline & $\begin{array}{l}\text { Parte } \\
\text { aérea }\end{array}$ & Raiz & Total & & & $\begin{array}{l}\text { Parte } \\
\text { aérea }\end{array}$ & Raiz & Total \\
\hline $\begin{array}{l}\text { T1-Substrato } 20 \text { dias } \\
\text { antes da semeadura }\end{array}$ & $5,8 \mathrm{ab}^{*}$ & $13,6 \mathrm{a}$ & $19,3 \mathrm{a}$ & $1,2 \mathrm{a}$ & $4,1 \mathrm{a}$ & $66,5 \mathrm{a}$ & $25,0 \mathrm{a}$ & $91,5 \mathrm{a}$ \\
\hline $\begin{array}{l}\text { T2-Substrato } 20 \text { dias } \\
\text { após da semeadura }\end{array}$ & $5,9 \mathrm{ab}$ & $12,3 \mathrm{ab}$ & $18,2 \mathrm{a}$ & $1,2 \mathrm{a}$ & $4,3 \mathrm{a}$ & $68,0 \mathrm{a}$ & $26,0 \mathrm{a}$ & $94,0 \mathrm{a}$ \\
\hline T3-Semente & $6,3 a$ & $11,9 \mathrm{ab}$ & $17,9 \mathrm{a}$ & $1,2 \mathrm{a}$ & $4,1 \mathrm{a}$ & $62,9 a$ & $27,0 \mathrm{a}$ & $89,7 \mathrm{a}$ \\
\hline T4-Substrato & $5,1 b$ & $11,4 \mathrm{ab}$ & $16,5 \mathrm{a}$ & $1,1 \mathrm{a}$ & $4,0 \mathrm{a}$ & $51,0 \mathrm{a}$ & $21,0 \mathrm{a}$ & $72,0 \mathrm{a}$ \\
\hline T5-Testemunha & $5,8 \mathrm{ab}$ & $11,1 b$ & $16,9 a$ & $1,3 \mathrm{a}$ & $3,8 \mathrm{a}$ & $59,0 \mathrm{a}$ & $21,5 \mathrm{a}$ & $80,5 \mathrm{a}$ \\
\hline $\mathrm{CV} \%$ & 17 & 12 & 10 & 17 & 13 & 26 & 35 & 27 \\
\hline
\end{tabular}

* Médias seguidas pela mesma letra nas colunas não diferem pelo teste de Duncan a $1 \%$ de probabilidade de erro. 


\section{CONCLUSÕES}

Trichoderma spp. coloniza $100 \%$ das sementes de canafístula controlando os fungos associados e proporcionando melhora na emergência das plântulas e maior número de folhas por muda, apresentando potencial para ser usado tratamento de sementes desta cultura.

\section{STATUS DA SUBMISSÃO}

Recebido: 6 ago., 2014

Aceito: 10 out., 2015

\section{AUTOR(ES) PARA CORRESPONDÊNCIA}

\section{Emanuele Junges}

Setor de Defesa Fitossanitária, Instituto Federal Farroupilha, Rua 20 de Setembro, s/n, CEP 97420-000, São Vicente do Sul, RS, Brasil e-mail: junges.emanuele@gmail.com

\section{REFERÊNCIAS}

Backes P, Irgang B. Árvores do Sul: guia de identificação é interesse ecológico. As principais espécies nativas SulBrasileiras. Santa Cruz do Sul: Clube da Árvore; 2002.

Bernardo ERA, Bettiol W. Controle da pinta preta dos frutos cítricos em cultivo orgânico com agentes de biocontrole e produtos alternativos. Tropical Plant Pathology. 2010; 35(1):37-42. http://dx.doi.org/10.1590/ S1982-56762010000100006.

Borges EEL, Castro JLD, Borges RCG. Avaliação fisiológica de sementes de cedro submetidas ao envelhecimento precoce. Revista Brasileira de Sementes 1990; 12(1): 56-62. http://dx.doi.org/10.17801/0101-3122/rbs.v12n1p56-62.

Brasil. Ministério da Agricultura, Pecuária e Abastecimento. Secretaria de Defesa Agropecuária. Regras para análise de sementes. Brasília: MAPA; 2009. 395 p.

Carvalho LF, Medeiros-Filho S, Rossetti AG, Teófilo EM. Condicionamento osmótico em sementes de sorgo. Revista Brasileira de Sementes 2000; 22(1): 185-192. http://dx.doi. org/10.17801/0101-3122/rbs.v22n1p185-192.

Carvalho PER. Espécies arbóreas brasileiras. Colombo: EMBRAPA: CNPF; 2003. 1039 p.

Faria AYK, Albuquerque MCF, Cassetari D No. Qualidade fisiológica de sementes de algodoeiro submetidas a tratamento químico e biológico. Revista Brasileira de Sementes 2003; 1(25): 121-127. http://dx.doi.org/10.1590/ S0101-31222003000100019.
Ferreira DF. SISVAR - Sistema de análise de variância. Versão 5.3. Lavras: UFLA; 2010.

Fortes FO, Silva ACF, Almança MAK, Tedesco SB. Promoção de enraizamento de microestacas de um clone de Eucalyptus sp. por Trichoderma spp. Revista Árvore 2007; 31(2): 221-228. http://dx.doi.org/10.1590/S010067622007000200004 .

Harman GE. Myth and dogmas of biocontrol changes in perceptions derived from research on Trichoderma harzianum T-22. Plant Disease 2000; 84(4): 377-393. http://dx.doi.org/10.1094/PDIS.2000.84.4.377.

Harman GE, Howell CR, Viterbo A, Chet I, Lorito M. Trichoderma species - opportunistic, avirulent plant symbionts. Nature Reviews. Microbiology 2004; 2(1): 43-56. http://dx.doi.org/10.1038/nrmicro797. PMid:15035008.

Howell CR, De Vay JE, Garber RH, Batson WE. Field control of cotton seedling diseases with Trichoderma virens in combination with fungicide seed. The Journal of Cotton Science 1997; 1: 15-20.

Maciel CG, Muniz MFB, Santos AF, Lazarotto M. Deteç̧ão, transmissão e patogenicidade de fungos em sementes de angico-vermelho (Parapiptadenia rigida). Summa Phytopathologica 2012; 38(4): 323-328. http://dx.doi. org/10.1590/S0100-54052012000400009.

Mafia RG, Alfenas AC, Maffia LA, Ventura GM, Sanfuentes EA. Encapsulamento de Trichoderma inhamatum para o controle biológico de Rhizoctonia solani na propagação clonal de Eucalyptus. Fitopatologia Brasileira 2003; 28(1): 101-105. http://dx.doi.org/10.1590/S0100-41582003000100016.

Mastouri F, Björkman T, Harman GE. Seed treatment with Trichoderma harzianum alleviates biotic, abiotic, and physiological stresses in germinating seeds and seedlings. Phytopathology 2010; 100(11): 1213-1221. http://dx.doi. org/10.1094/PHYTO-03-10-0091. PMid:20649416.

Nakagawa J, Mori ES, Pinto CS, Fernandes KHP, Seki MS, Meneghetti RA. Maturação e secagem de sementes de Peltophorum dubium (Spreng.) Taubert (CANAFÍSTULA). Revista Árvore. 2010;34(1): 49-56. http://dx.doi.org/10.1590/ S0100-67622010000100006.

Oliveira LMD, Davide AC, Carvalho MLM. Avaliação de métodos para quebra da dormência e para a desinfestação de sementes de canafístula (Peltophorum dubium (Sprengel) Taubert. Revista Árvore 2003; 27(5): 597-603. http://dx.doi. org/10.1590/S0100-67622003000500001.

Patekoski KS, Pires-Zottarelli CL. Patogenicidade de Pythium aphanidermatum a alface cultivada em hidroponia e seu biocontrole com Trichoderma. Pesquisa Agropecuaria Brasileira 2010; 45(8): 805-810. http://dx.doi.org/10.1590/ S0100-204X2010000800005.

Prates HS, Cesmik R, Ferraz JMG. Trichoderma spp. no controle de doenças de plantas. Brasilia: Embrapa; 2006. Folder Técnico SAA/Embrapa. 
Prates HS, Lavres J Jr, Rossi ML. Composição mineral de mudas cítricas com aplicações de Trichoderma spp. São Paulo: International Plant Nutrition Institute; 2007. 118 p. Folder Técnico IPNI.

Salerno AR, Schallenberger TCH, Stuker H. Quebra da dormência em sementes de Canafístula. Agropecuária Catarinense. 1996; 9(1): 9-11.

Sarmento MB, Villela FA. Sementes de espécies florestais nativas do sul do Brasil. Informativo Abrates 2010; 20(12): 39-44.
Silva PRQ. Transformação de Trichoderma harzianum com os genes egfp e tubulina [dissertação]. Brasília: Universidade de Brasília; 2000.

Sivan A, Chet I. The possible role of competition between Trichoderma harzianum and Fusarium oxysporum on rhizosphere colonization. Phytopathology 1989; 79(2): 198-203. http://dx.doi.org/10.1094/Phyto-79-198.

Takada HM. Tratamento de substrato e fontes de água sobre a severidade de Rhizoctonia sp. em plântulas de eucalipto. Arquivo Instituto Biológico 2004; 71(Supl): 1-749. 